\title{
Effects of a Centered Virtual Teaching Environment on Learning Styles in the Academic Performance of College Students
}

\author{
doi:10.3991/ijet.v4s1.809
}

\author{
F. Iriarte Díaz-Granados, E. Dominguez, C. Ricardo, B. Ballesteros y H. Fontalvo \\ Universidad del Norte, Barranquilla, Colombia
}

\begin{abstract}
Based on the concept of adaptive hypermedia, the webCT platform was used to design a learning virtual environment that would allow students' interaction of different support materials with their usual styles of learning. GA Latin Square design was used to determine the role that environment and learning styles, along with intrinsic motivation, played on academic performance, navigation patterns, and number of visits to the support materials.
\end{abstract}

The study showed an important difference in academic performance in favor of the Balanced group. Intrinsic motivation was the main explicative factor for the differences found beyond learning styles. The conclusion was that there are differences in the way of using the objects of learning, and that there are differentiated patterns to access the support material, depending on the students' learning styles.

Index terms-Virtual learning, learning styles, intrinsic motivation, adaptive hypermedia.

\section{INTRODUCTION}

Admitting the role of ICT in today's education, not only has generated an explosion of learning, where "the demand for knowledge becomes a key factor in determining prosperity, security and quality of life by using those media that allow rapid exchange of information" [1], but also requires a need for clarity and vision concerning its dynamic evolution as a mediation for learning.

Along with the concerns for the effects that ICT may have in general on education, stands the question if these new opportunities actually meet the interest and motivation of today's college students. In fact, their identity is partly defined by the books they read, but mainly by the television programs they watch and the multimedia hypertexts they consult on the Internet every day.

\section{Conceptual Frame}

\section{A. Learning styles:}

The studies carried out to establish a duly documented basis for the concept of learning styles began in the seventies. By then, the writings of Rita and Kenneth Dunn, and those of David Kolb, had been published in 1972 and 1971 respectively [2]. These early publications led to further research on the subject, with different proposals on the concept on learning styles, based on other scientific methods. This is how theories and definitions on learning styles became stronger. Dunn had stated that "The styles of learning are the ways in which each person absorbs and retains information and skills; regardless of how that process is described, it is dramatically different for each person." [3] Let us observe in this statement by Dunn, that by that time there already existed a number of possibilities that would appear with the development of the various concepts on the styles of learning. With time, these would become the theories we know today.

For Kolb, whose theory has been acknowledged as one of the forerunners of all subsequent postulates on styles, learning was a circular process; the product of a series of experiences with cognitive factors, such as concrete experiences, reflection and observation, abstract concepts, generalizations, and active experimentation [4].

Honey and Mumford (1986) would extend David Kolb's theory towards a more psychological perspective, by proposing an initial classification of learning styles, basically: the active, the reflective, the theoretical and the pragmatic. The active would be the individual that learns in a dynamic way, the reflective one who does so in a creative way, the pragmatic in a rational way, and the theoretical in an analytical way [4].

Shortly after, for [5], learning styles would be defined as departing from a cognitive basis, in a mainly educational field of application: "learning styles are cognitive, affective, and psychological traits that serve as indicators to establish the way in which a student perceives, interacts with, and responds to, the learning environment. This is revealed in the way an individual behaves and performs in a learning experience.”

It is clear that for this and later authors, a learning style implies a number of factors related to internal and external processes originated in the personality, which involves the neurobiological conditions of the individual and his/her development, in a permanent manifestation of inherited traits mixed with the influence exerted by the environment.

\footnotetext{
* This essay was carried out thanks to the financial support of the Instituto Colombiano para el Desarrollo de la Ciencia y la Tecnología
} (COLCIENCIAS). 
The application of new research findings generate more elaborate classifications of styles, gathering samples of students from all academic levels (elementary, secondary and high school, technical, and college) in order to new ways of teaching-learning (virtual education and use of the Web), or of simply improving the quality of learning a second language or pursuing a specific career (engineering, mathematics, communications.)

\section{B. Adaptive hypermedia}

Learning adaptive hypermedia systems are softwares that can design information for users according to a detailed model of individual objectives, interests, and preferences [6]. Basically, there are two large types of hypermedia adaptation: adaptive presentation and adaptive navigation support [7]. Adaptive presentation refers to adaptation within the contents of learning, starting from the user's needs and abilities. "The idea behind adaptive presentation is to personalize the course contents according to the specific characteristics of the students, generating new user models.” (British Journal of Educational Technology, 2003.) As to adaptive navigation support, is that which is present at navigation structure levels.

Educational hypermedia systems have existed for more than two decades, modeling students' learning styles. The system developed by Carver [8] is based on the FelderSilverman model to design course components, hypertexts, clips, multimedia, and so on. Depending on the student's style of learning, the system presents a list of course components with links that users can explore by clicking on them [9].

In presenting the material for a course, the Arthur system [10] uses four styles of learning: auditive, visual, kinesthetic, and a combination of the three. When a student enters the system for the first time, course contents are presented at random; then, the system monitors the student's learning process and makes a detailed evaluation in order to determine the student's learning style (auditive, visual, kinesthetic, or a combination of the three.) Depending on the learning style the system provides the appropriate contents [9].

Another system, the Adaptive Courseware Environment - ACE- [11] provides certain mechanisms adapted to the learning styles of the students. When exploring a new course, the student has to answer a number of questions about his learning strategies --for example, if he learns better through readings, through activities, or through examples. Based on the student's learning style models, the server submits the appropriate learning units and generates hypermedia documents for that specific student. Following each of the general principles of the educational theory on learning styles, the server is capable of classifying the learning units according to each student's preferred style.

\section{PRoblems AND OBJeCtives}

Many of the systems developed have different ways of gathering information on the learning styles of students, from interviews and questionnaires to monitoring student's behavior. However, an important point to keep in mind is that the analysis of the students' learning styles must be carried out with the use of specialized psychological tests and not with mere interviews [12].
Present investigations have focused on the analysis of the variations in motivation, metacognition, styles of learning, cognitive styles, and other variables within the academic models considered as determinant factors in student performance. More recently, evidence has shown that presenting information in different ways leads to a more effective instruction [13]. In order to respond to these requirements, several systems have been developed, such as the 3DE (Design, Development and Delivery Electronic Environment for Educational Multimedia), which has the purpose of creating, either in an automatic or a guided way, courses adapted to each student's learning style. This initiative was considered in the $\mathrm{V}$ Frame Program of the European Union, with the participation of COREP (Turin Polytechnic), ARDEMI (France), STI (Spain), and Vaasa Polytechnic (Finland.) There is also the adaptive intelligent tutoring system, that considers the (MAS-PLANG) learning styles; it uses the FSLSM Model [14], [22] to categorize students according to their ability to process, perceive, receive, organize and understand information, and offers didactic contents, navigation tools and navigation strategies adapted to the characteristics of these learning styles by using intelligent agents.

Each of these systems becomes an alternative to generate virtual teaching-learning environments that consider each student's way of learning. However, careful investigation is required to estimate the real impact on the students' learning processes.

The investigation oriented to determine the influence that a virtual learning model focused on the styles of learning exerts on the academic performance of college students, opens the door to a broader outlook of the conditions that the teaching-learning processes should have in an institution that is interested in enhancing its formative processes through the use of new technologies.

Virtual teaching and learning, as considered in this project, will permit teachers and students to interact with those tools that have become habitual to their activities, and to appropriate them with a critical eye.

The main objective of this study was to determine the influence that a virtual learning model, focused on the styles of learning, exerts on the academic performance of college students.

The specific objectives were to determine the levels of cognitive appropriation as well as the differences in academic performance, depending on the learning styles and the levels of intrinsic motivation of the college students that took part in a virtual learning model centered on different learning styles.

\section{METHODOLOGY}

The investigation was defined on the quantitative paradigm of analytical character. Being coherent with this paradigm, we used a quasi-experimental design in order to estimate the effects of treatment variables within an educational context, where aleatorization of the units/subjects is not always possible and the effective control of explication alternative sources is difficult [15],

The experimental group was conformed by $9^{\text {th }}$ semester male and female students enrolled in different engineering programs. Seventy-five students took the course called "Cleaner Production”, designed as a virtual course. 
At the moment of starting the investigation, we worked with the ninth semester's natural group; in other words, with the entire population; therefore, we used an intentional, non-probabilistic sampling. All the students took part under experimental conditions, but not all of them became the object of analysis. The sample used for analysis was conformed by the 48 students with the most clearly defined styles.

The instrument used for the evaluation of the learning styles was the Felder- Silverman Learning Styles Questionnaire [14]. This questionnaire has been widely validated in different countries with different types of student populations.

In order to evaluate motivation towards learning we used the MAPE-II Scale: Motivation for Learning and Performance [16]. It is a questionnaire based on the Dweck-Elliot theory [17] of six scales with proven, highly acceptable coefficients of internal consistency. The consistency of the superior order scales is the largest. These scales are: capacity of work and performance (15 items), intrinsic motivation (16 items), ambition (13 items), inhibitory performance anxiety (12 items), facilitating performance anxiety (12 items), and vagrancy (12 items.) For the analysis in this project we used the results of the intrinsic motivation scale.

We used the following instruments for the evaluation of academic performance:

Specific test on knowledge: based on the themes of the course "Cleaner Production." The objective was evaluation, before and after the virtual learning experience. There was a specific test on knowledge for each unit, built on psychometric criteria established for this purpose.

Guide for the valoration of motivation and interaction with units: a qualitative guide prepared in order to obtain information on the motivation each student had during the process of interaction with the model.

Rubrics for the valoration of cognitive processes: designed in order to determine the levels of the students' cognitive appropriation in the units studied. The evaluation on cognitive processes and valoration levels was assigned to expert judges who were in the cognition and education research group. The cognitive processes evaluated were: knowledge, analysis, synthesis, application, and valoration.

Having chosen the instruments, we proceeded to determine the learning styles of the students that would take part in the study. With these results, we designed the objects of learning, centered on the factors with higher tendency and their combinations. In this case the Visual, Sensitive-Visual, and Active-Visual.

Then, we took units 6 and 7, and fragmented them in order to develop the learning objects, within the dimensions that had been established. For the design and development of the learning objectives we kept in mind the National Ministry of Education' criteria.

Taking this referent as basis, the working scheme of Unit 6 was developed as follows:

For the contents on the first subject, "Tools for the Implementation of a Cleaner Production System” we used Flash, a conceptual map accompanied by an explanation in audio, created for the users in the Visual group. This map made a graphic synthesis of the theme, with emphasis on the main concepts involved. The same conceptual map was presented to the Sensitive-Visual group, along with some examples of each of the concepts. Finally, the Active-Visual group received a map of ideas where each student had to put in order the concepts presented in a predetermined paragraph.

Then came the design of the materials for the contents of the subject "Definition of Main Environmental Tools", developed in the following formats: Echo-indicators = Presentation in Flash with audio. Environmental audits = Design of a mental map along with audio and links. Echodesigns and Echo-tags = Conceptual map along with audio. Environmental initial revision = Ecomapping, Ecobalances, MatrizMed scheme.

Here, the construction of the learning object started from a Flash platform, presenting a scheme that was accompanied by a guide in audio.

Each design was revised by the members of the research group and submitted for technical corrections (images, backgrounds, temporality, and so on.)

Then, we developed the learning activities of the module with the supervision of the corresponding instructor.

\section{A. Implementation of the investigation process.}

Having covered the steps for the conformation and formalization of the research team, the training of the teachers that applied the virtual model and the design of the teaching-learning virtual environment, as well as the object of the activities, we proceeded with the implementation of the virtual learning model focused on the styles of learning.

In order to do this we proceeded as follows:

For the first unit chosen, we organized the study materials in such a way that students with a balanced learning style had access to a specific type of material, while those with a visual style had access to a different type of material. There was no possibility for students to consult both styles.

Then the students took a knowledge pre-test and a posttest on for the first unit given (Unit 6.)

Next, there were learning activities for all the students, with emphasis on the processes of analysis, synthesis, evaluation, application, and verification of knowledge.

For the second unit chosen, we organized the study materials in such a way that all the students had access to the different material presentation formats prepared for this unit.

Again, there was a knowledge pre-test and post-test for this second unit (Unit 7.)

There were learning activities for all the students, with emphasis on the processes of analysis, synthesis, evaluation, application and verification of knowledge. These data were not used for comparison between the results of the units, since the contents of Unit 7 were different from those of Unit 6. However, they were considered for the unit analysis, and also to extend the possibility of finding navigation patterns and frequency of visits to the different learning objects. 


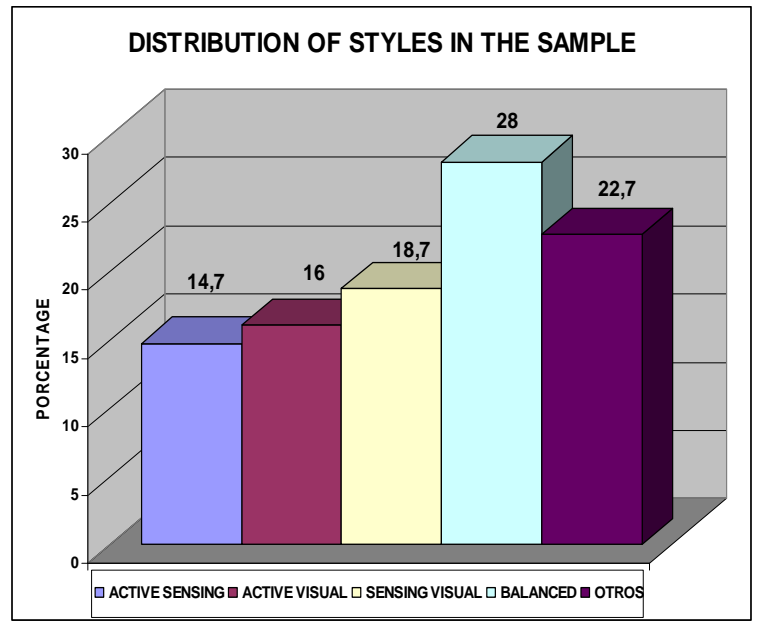

Figure 1. Distribution of the styles obtained from the students sample groups

\section{RESUlts}

In this study we worked with the balanced and the visual groups.

To perform the statistical analysis was used SPSS for Windows, version 11.5.

In order to determine if such differences were meaningful between the two styles with regard to academic performance in Unit 6, we first applied the variation homogeneity test. Chart 1 shows that at a level of signification of $5 \%$, the error variations in both population groups are identical.

TABLE I.

VARIANCE HOMOGENEITY TEST

\begin{tabular}{|c|c|c|c|}
\hline \multicolumn{4}{|c|}{ Academic performance } \\
Statistics of Levene & gl1 & gl2 & Sig \\
\hline, 517 & 1 & 32 &, 477 \\
\hline
\end{tabular}

After completing the homogeneity requirement, we applied the variance analysis of one factor, the results of which are shown in Chart No. 2. Assuming signification level of $5 \%$, the $\mathrm{F}$ obtained $(5,081, \mathrm{p}=0,031)$, indicates that the difference observed in the groups' average is significant, in this case in favor of the balanced learning style. The conclusion is that there are tests that indicate that the style of learning have some effect on the students' academic performance.

TABLE II. ANOVA

\begin{tabular}{|c|c|c|c|c|c|}
\hline & $\begin{array}{c}\text { Sum of } \\
\text { squares }\end{array}$ & gl & $\begin{array}{c}\text { Quadratic } \\
\text { media }\end{array}$ & F & Sig. \\
\hline Inter-groups & 1,836 & 1 & 1,836 & 5,0 & 0,31 \\
Intra-groups & 11,560 & 32 &, 361 & & \\
\hline Total & 13,396 & 33 & & & \\
\hline
\end{tabular}

This result supports Cantu's affirmation [18], that the academic accomplishment of students, as expressed by their performance, exerts a positive influence on some, and a negative influence on others. In our concept, there is an important correlation between academic performance and the student's learning style.
In order to determine if there were differences in the performance of each of the evaluated cognitive processes between the learning style groups, we used the variation analysis of one factor again. In this case, only the two cognitive processes where differences were found are presented. The average of the balanced group $(3,294)$ in Cognitive process seems to be higher that that of the visual style $(2,565$.) The same happens with the average of the balanced style $(3,294)$ in relation to the visual style $(2,953)$ in the Analytical process.

To determine if such differences were significant, we first proceeded to apply the variation homogeneity test which, at a significance level of 5\%, showed that the error variations of the groups at population level are identical.

After verification of the variance homogeneity, we carried out the analysis. For a determined significance level of $5 \%$, the $\mathrm{F}$ obtained for the Cognitive process $(5,435 . \mathrm{P}=0.031)$, indicates that the difference observed in the groups' average is significant, in this case in favor of the balanced learning style. The same occurs with the Analytical process, whose F obtained for the same level of significance was 7,879 ( $p=0,008$.) The conclusion is that some tests can indicate that the learning style has some effect on student performance during the process.

In order to determine if there were significant differences of performance in students with different levels of motivation and different learning styles, we conformed two subgroups of the visual style, adding a dimension with some predominance other than the visual. Based on this criterion, the groups were: active-visual, sensitive-visual, and the balanced. For these subgroups, we established levels of intrinsic motivation (high-4, medium-3, and low $=2$ ) towards studying, conforming a design of Latin Square. The statistical instrument used to make a contrast of the corresponding hypothesis was the Univariant General Lineal Model or Univariant Analysis of Variance.

In the descriptive statistics of data we can observe that there do not seem to be differences between the learning style subgroups with a total mean of 3,308, 3,083, and 3,442 , respectively. This is not the same in the case of the intrinsic motivation factor, whose total mean seems to be different, especially those pertaining to the first and third motivation levels (2,983 and 3,523.) The Levene Test (F,905, Sig=,527) indicates that the null hypothesis can be accepted. This means that assuming equal variance of error, the F test is valid and can be applied without restrictions.

After carrying out the inference test, we found that the model may explain a variance proportion beyond the expected by random effect. In this case, the null hypothesis is rejected for the motivation level $(\mathrm{F}=4,097$, $\mathrm{p}<0.05)$, but accepted for style levels $(\mathrm{F}=1,872, \mathrm{p}>0.05$.) These results suggest that motivation levels have an effect on student academic performance, regardless of their learning styles.

These results support those found by [19], who studied the learning styles of students taking courses on the web associated with their own learning style. They conclude that learning styles of students and their characteristics, do not have an effect on their achievements based on web learning. In other words, the authors conclude that students with different learning styles and previous knowledge, learned the same with web based courses, and 
that the styles of learning did not affect student motivation or learning strategies. Those found in [20] support the same, concluding that learning styles in a web environment do not show significant differences between the groups when comparing their learning styles and achievements.

In general, it seems that online student behavior is guided by intrinsic motives, rather than by the advantages that they would find in a traditional class. This indicates that the success of online students depends on other factors, apart from learning styles.

\section{CONCLUSIONS}

In the first place we must state that the learning styles found in the sample have the same variability as in other studies carried out on this matter.

Since the groups belonged to engineering students, the results support such research as that of [21], who have observed the preference of learning styles in students of various types of engineering and in students of electrical engineering technology and computer science. In these studies they have found that computer science students are inclined for the active, visual (in a high degree), and sequential styles. However, the styles preferred by both groups were definitely the active and sensitive, with important differences between the visual and sequential styles, which are similar to the results found in our study.

Concerning the relationship between styles of learning and academic performance, we found an important difference in favor of the balanced group, a result which is supported by those of [18], for whom the interaction of the learning style exerts a positive influence in the academic performance of some students, and a negative influence on other students. For this author, there is an important correlation between academic performance and learning style. In this case, we also support the general concept that the balanced style shows a better performance than those with a strong predominance in some of the dimensions used, whether it is to perceive or process information.

Knowing the different learning styles is important and valuable, because they can give us clues in the design and planning of formation contexts, even to reach considerations as those here exposed, which may be of great value in any kind of educational sceneries through the Internet.

\section{REFERENCES}

[1] J.J.Duderstadt, (1997). "The future of the university in an age of knowledge". Obtained in the address: www.aln.org/alnweb/jour nal/issue2/duderstadt.htm

[2] Roberta L. Watson Margaret F. Williamson, (2006). Learning Styles Research: Understanding How Teaching Should Be Impacted by the way learners learn. Christian Education Journal. ProQuest Education Journals pg. 27

[3] Dun, R. y Dun, K.(1984): La Enseñanza y el Estilo Individual de Aprendizaje. Anaya, Madrid.

[4] Fatt, J. and Joo, N. (2001) Learning Styles: implications for design and technology education. Management. Research News, 24 (5), 24-37. (doi:10.1108/01409170110782414)

[5] Keefe, J. W. (1988). Profiling and utilizing learning style. Virginia: NASSP.
[6] F.Paternò, C.Mancini, "Designing Usable Hypermedia", Empirical Software Engineering, Vol.4, N.1, pp.11-42, Kluwer Academic Publishers, 1999. A.Lecerof, F.Paternò, "Automatic Support for Usability Evaluation", IEEE

[7] Brusilovsky, P. Alfred Kobsa, J. V. (1998). Adaptive Hypertext and Hypermedia, First Edition.

[8] Carver,C. A., Howard, R. A., Lane, W.D. (1999). Addressing Different Learning Styles Through Course Hypermedia. IEEE Transactions on Education 42(1), 33-38. (doi:10.1109/13.746332)

[9] Kinshuk and Taiyu Lin and Paul McNab (2004) Modelling Inductive Reasoning Ability for Adaptive Virtual Learning Environment. CELDA 2004 : 343-349

[10] GILBERT, J. E. \& HAN, C. Y. (1999). Adapting Instruction in Search of "A Significant Difference". Network and Computer Applications, 22, 149-160. (doi:10.1006/jnca.1999.0088)

[11] Specht, Marcus/Reinhard Oppermann (1998): ACE - Adaptive Courseware Environment. The New Review of Hypermedia and Multimedia, 4 (1998), 1, 141 -161.

[12] Brusilovsky, P. (2001). Adaptive Hypermedia. User Modeling and User Adapted Interaction, Vol. 11 (1/2), 87-110. (doi:10.1023/A:1011143116306)

[13] Saarikoski, L.; Salojärvi, S.; Del Corso, D.; Ovcin, E. (2001): "The 3DE: An Environment for the Development of LearnerOriented Customised Educational Packages”. ITHET, 4-6 Julio, 2001, Kumamoto. www.eecs.kumamoto-u.ac.jp/ITHET01/procee dings.htm

[14] Felder, Richard. Silverman, Linda (1988) Learning and teaching styles in engineering education. En: Education, 78(7), 674-681

[15] Balluerka, N. y Vergara, A. (2002). Diseños de investigación experimental en Psicología. Madrid: PreTICe Hall.

[16] Alonso Tapia, J. (1995) Evaluación del conocimiento y orientación educativa. En Alonso Tapia (1995), Orientación educativa. Teoría, evaluación e intervención (pp.57- 109). Madrid: Síntesis Psicología.

[17] Dweck, C.S.; Elliot, E.S. (1983) Children's theories of intelligence: Impact on learning. En S.G. Paris, G.M. Olson, H.W. Stevenson (Eds.) Learning and motivation in the classroom, Hillsdale: New Jersey-EE.UU.

[18] Cantú Hinojosa, Irma Laura. (2004). El estilo de aprendizaje y la relación con el desempeño académico de los estudiantes de arquitectura de la UANL. Universidad UANL.

[19] Shih,C y Thompson, A. (2000). Student use of learning strategies in web-based courses. Proceedings of the International Conference on Computers in Education /Computer Assisted Instruction. Taipei (Taiwan) pp. 1476-1480.

[20] Sarkozi, G. (2002). A Study of Critical Learning: Incidents in a Traditional Classroom and in an Asynchronous Online Format. International Research Conference on Distance and Adult Learning. The Open University of Hong Kong, Homantin, Kowloon, Hong Kong.

[21] Paul I-Hai Lin (2006). Learning Styles of Electrical and Computer Engineering Technology Students. Journal of Engineering Technology. Spring 2006

[22] Fabregat, R. Marzo, J.L. Peña, C.Teaching Support Units Computers and Education in the 21st Century: Kluwer Academic Publishers, 2000, pp. 163-174.

\section{AUTHORS}

F. Iriarte Díaz-Granados, E. Dominguez, C. Ricardo, B. Ballesteros, and H. Fontalvo are with the Universidad del Norte, Barranquilla, Colombia.

This article was modified from a presentation at $\mathrm{X}$ International Symposium on Computers in Education (SIIE2008) 1st-3rd October 2008, Salamanca, Spain. Manuscript received 19 January 2009. Published as submitted by the authors. 